\title{
EL TEATRO COMO DOCUMENTO ARTÍSTICO, HISTÓRICO Y CULTURAL EN LOS INICIOS DEL SIGLO XXI
}

\author{
José ROMERA CASTILLO (ed.)
}

(Madrid: Verbum, 2017, 555 págs.)

El teatro como documento artístico, histórico y cultural en los inicios del siglo XXI, volumen editado por José Romera Castillo, recoge las sesiones plenarias y las comunicaciones presentadas por prestigiosos investigadores y artistas del ámbito hispano, tanto de universidades españolas como europeas y americanas, en el XXV Seminario Internacional del SELITEN@T, que tuvo lugar del 28 al 30 de junio de 2016, en la Facultad de Filología de la Universidad Nacional de Educación a Distancia (UNED) de Madrid, bajo la dirección del propio José Romera Castillo, con la colaboración de Francisco Gutiérrez Carbajo y la coordinación de Raquel García-Pascual.

El Centro de investigación de Semiótica Literaria, Teatral y Nuevas Tecnologías, SELITEN@T, hasta la fecha ha celebrado veinticinco ediciones del Seminario anualmente, en los que ha estudiado, con profundidad y amplitud, numerosos asuntos relacionados con el teatro del siglo XXI desde un punto de vista semiológico, tomando en consideración tanto los textos dramáticos como los restantes elementos que conforman los textos escénicos o de la representación, esto es, lo textual y lo espectacular. Por ello, las líneas de investigación del centro son muy diversas, desde la reconstrucción de la vida escénica en España y la presencia del teatro español en Europa e Iberoamérica durante los siglos XIX, XX y XXI, hasta el análisis de otros muchos aspectos relacionados con la literatura, la escritura autobiográfica y las relaciones entre la literatura y las nuevas 
tecnologías. De esta manera, el SELITEN@T se ha convertido en uno de los centros de investigación que más trabajos ha dedicado al estudio del teatro español actual.

El teatro como documento artístico, histórico y cultural en los inicios del siglo XXI se divide en tres apartados: en el primero, el lector encontrará un panorama del teatro como documento artístico, histórico y cultural en España y sus puestas en escena, así como diferentes propuestas teóricas. En el segundo, dramaturgos del máximo prestigio en la escena española contemporánea analizan su producción dramática como teatro documento. $\mathrm{Y}$ en el tercer y último apartado, son examinados otros aspectos de dicho género, como algunos autores, obras, compañías y puestas en escena.

José Romera Castillo da cuenta de la historia de los veinticinco años de Seminarios internacionales que ha dirigido, de los cuales dieciséis han estado dedicados al estudio del teatro representado desde la segunda mitad del siglo XX hasta nuestros días, y han tratado, entre otros asuntos, las relaciones entre el teatro y otras artes como el cine o la televisión, las nuevas tecnologías, las dramaturgias femeninas, el teatro de humor y el teatro breve.

El dramaturgo Jerónimo López Mozo traza un "Mapa del teatro documento en los albores del siglo XXI en España”, partiendo de la definición del género realizada por Peter Weiss en 1968 y de sus variantes posteriores, de tal modo que informa de la presencia total o parcial de lo documental en el teatro español del presente siglo.

En "El teatro documental en la cartelera teatral de $A B C$ Madrid (2000-2016)", el Grupo de investigación del SELITEN@T formado por Nerea Abusto González, Jesús Ángel Arcega Morales, Ricardo de la Torre Rodríguez, Juan Carlos Romero Molina, Olivia Nieto Yusta y Miguel Ángel Jiménez Aguilar, dirigido por Romera Castillo, da a conocer dicha cartelera a partir de los datos ofrecidos por ABC Madrid y ABC Cultural.

Arno Gimber, de la Universidad Complutense de Madrid, centra su interés en "Los expertos en el teatro documento postdramático", quienes, a su juicio, son personas reales que comunican sus experiencias en el ámbito profesional desde el escenario, sin que interpreten ningún papel y tomando como documento aspectos de su biografía.

Juan Pedro Enrile Arrate, de la RESAD, propone establecer dos paradigmas del teatro documento en las posmodernidad: uno argumentativo, cuyo objetivo es la defensa de una tesis ante el público, como en el caso 
de Libres hasta el final, dirigido por el propio Enrile Arrate y Paz Buelta; y otro relacional, en el que este debe responder a situaciones que rebasan el marco teatral convencional, como ocurre, según el estudioso, con la $R e$ tórica de Aristóteles o la Institutio Oratoria de Quintiliano de Calahorra.

"La tragedia española: entre teatro discursivo y teatro asociativo" da título al estudio de Ana Contreras Elvira y Alicia Blas Brunel, de la RE$\mathrm{SAD}$, en el que hacen visible los textos dramáticos que han luchado contra el olvido de lo que fue la represión franquista, como en el caso de Los vivos y los m(ios), de José Cruz, La entrega de Madrid, de Rubén Buren, y Exhumación, materia cruda, de Mercedes Herrero.

Ya en la segunda parte, el dramaturgo y presidente de la Academia de las Artes Escénicas de España, José Luis Alonso de Santos, describe la dramaturgia de una de sus obras documentales en "Sobre Los conserjes de San Felipe (Cádiz, 1812) y su proceso de escritura". El también autor de teatro, además de director y escenógrafo Jesús Campos García, en "Vestigios emocionales", reflexiona en torno al concepto de documento y su relación con lo teatral, y se desmarca como creador de este tipo de teatro. En "Mi último teatro como documento", la dramaturga Paloma Pedrero describe sus obras de teatro como documento de las vivencias de seres humanos reales más recientes, concretamente Caídos del cielo, Androide mío y Ana el once de marzo. El dramaturgo Alberto Conejero López profundiza en las claves de las poéticas y las estrategias dramatúrgicas -la autoficción, el impersonaje, la retrospección analéptica y la hiperlepsis- de cuatro de sus textos, que califica de "dramaturgia de la ausencia": Cliff (Acantilado), La piedra oscura, La extraña muerte de una cuplitista contada por su perro y Ushuaia. El también dramaturgo Fernando J. López ofrece un recorrido por su producción dramática, desde Cuando fuimos dos hasta Los amores diversos, por cuanto este, su teatro, sirve como "documento de la visibilidad" del mundo LGTBI, huyendo del panfleto y los clichés, y tratando de lograr la empatía de la escena con el público a través de la acción dramática. Por su parte, la dramaturga Eva Guillamón, entre otros asuntos relacionados con el teatro y la creación, refiere su experiencia como autora del espectáculo El flamenco es un animal salvaje, en el que conjuga la poesía con el teatro documental a partir de artículos periodísticos. Y cerrando este apartado, Rafael Negrete Portillo, de la Universidad Europea de Madrid, propone un acercamiento al concepto de "teatro cubista", generador de documentos históricos y culturales, desde la perspectiva de la escritura 
dramática, como en el caso de su obra Último sujeto.

Ya en la tercera parte, el Profesor de la UNED Francisco Gutiérrez Carbajo profundiza en el teatro como documento de la cárcel en el panorama dramático actual. La investigadora Pilar Jódar Peinado relaciona el teatro documento con el metateatro y lo aplica a siete textos teatrales del siglo XXI. María Bastianes, de la Universidad Complutense de Madrid y el ITEM, estudia el valor documental de La Celestina en diferentes puestas en escena recientes. El investigador F. Javier Bravo Ramón analiza como documentos los espectáculos presentados en la II edición del proyecto Ensayando un clásico del Festival de Almagro. Rosa Avilés Castillo, de la Universitat de Barcelona, centra su atención en la versión de Fuente Ovejuna de Juan Mayorga; Emilie Lumière, de la Université Toulouse 2 Jean Jaurès, en El cartógrafo, del mismo autor; y Carmen Abizanda Losada, de la ESAD de Galicia, en el teatro político-social e histórico en la obra breve de este.

La investigadora Laura López Sánchez describe Las raíces cortadas de Jerónimo López Mozo como paradigma de teatro documento. José Ignacio Lorente, de la Universidad del País Vasco, expone el carácter documental de Protegedme de lo que deseo, de Rodrigo García. Carole Viñals, de la Universidad de Lille (Francia), estudia de similar manera El pan y la sal, de Raúl Quirós; Alma Prelec, de University of Oxford, La piedra oscura, de Alberto Conejero; y el investigador Carlos Herrera Carmona, textos dramáticos de Alberto Conejero, César López Llera y Paco Bezerra. Isabel Carabantes de las Heras, de la Universidad de Zaragoza, considera, por su parte, el tema de "la puerta giratoria" en algunos dramas actuales.

Julio Vélez-Sainz, de la Universidad Complutense de Madrid y el ITEM, describe el trabajo documental de Animalario y Teatro del barrio. Nortan Palacio Ortiz, de la Compañía Corrales de Comedias Teatro, estudia El Rey, de Alberto San Juan. En torno a El triángulo azul, de Mariano Llorente y Laila Ripoll, y otros textos giran los trabajos de Antonia Amo Sánchez, de la Université d'Avignon; Rosana Murias Carracedo, de la Universidad Herzen de S. Petersburgo y el SELITEN@T; y Simona Di Giovenale, de la Università degli Studi Roma Tre. Sobre el teatro de Angélica Liddell escribe Jesús Eguía Armenteros, del Marbella International University Center, y Antonio César Morón, de la Universidad de Granada. Mercè Ballespí Villagrasa, del Aula Municial de Teatro de Lleida, Ana María Díaz Marcos, de la Universidad de Connecticut, María José 
Sánchez Montes, de la Universidad de Granada, Ana Prieto Nadal, del SELITEN@T, la investigadora María Eugenia Matamala Pérez y Julio Fernández Peláez, de la Universidad de Alcalá de Henares, se centran en diferentes dramaturgias femeninas. Por último, la labor de creación del teatro documento que realizan diferentes compañías y dramaturgos tanto españoles como extranjeros es abordada en diversos estudios realizados por Marcos García Barrero, de la Universidad Autónoma de Madrid; la dramaturga Alicia Casado Vega; M. Reina Ruiz Lluch, de la Universidad de Arkansas; Josep Ramon Garcia I Ibáñez, de la Universitat de València; y Ewelina Topolska, de la Universidad Pedagógica de Cracovia (Polonia).

En definitiva, las Actas del XXV Seminario Internacional del SELITEN@Tseconvierten enunaguíaimprescindibleparaunconocimiento amplio y profundo del teatro como documento artístico, histórico y cultural en los inicios del siglo XXI, así como en un instrumento de investigación y de conocimiento fundamental para entender un fenómeno tan relevante y actual como el del teatro documento, en el contexto del mundo globalizado contemporáneo.

Miguel Ángel Jiménez Aguilar Grupo de Investigación del SELITEN@T 
